\title{
Article \\ Effect of Pre-Stretch on the Precipitation Behavior and the Mechanical Properties of 2219 Al Alloy
}

\author{
Guo-Ai Li ${ }^{1,2}$, Zheng Ma ${ }^{3}$, Jian-Tang Jiang ${ }^{3,4}$, Wen-Zhu Shao ${ }^{3,4}$, Wei Liu ${ }^{3,4}$ and Liang Zhen ${ }^{3, *}$ \\ 1 Beijing Institute of Aeronautical Materials, Beijing 100095, China; LLLDK3@163.com \\ 2 Beijing Engineering Research Center of Advanced Aluminum Alloys and Application, \\ Beijing 100095, China \\ 3 School of Materials Science and Engineering, Harbin Institute of Technology, Harbin 150001, China; \\ mz1081900114@163.com (Z.M.); jjtcy@hit.edu.cn (J.-T.J.); wzshao@hit.edu.cn (W.-Z.S.); \\ liuw@hit.edu.cn (W.L.) \\ 4 National Key Laboratory of Precision Hot Processing of Metals, Harbin Institute of Technology, \\ Harbin 150001, China \\ * Correspondence: lzhen@hit.edu.cn; Tel.: +86-451-8641-2133; Fax: +86-451-8641-3922
}

Citation: Li, G.-A.; Ma, Z.; Jiang, J.-T.; Shao, W.-Z.; Liu, W.; Zhen, L. Effect of Pre-Stretch on the Precipitation Behavior and the Mechanical Properties of 2219 Al Alloy. Materials 2021, 14, 2101. https://doi.org/10.3390/ma14092101

Academic Editor:

Krzysztof Karczewski

Received: 21 February 2021

Accepted: 9 April 2021

Published: 21 April 2021

Publisher's Note: MDPI stays neutral with regard to jurisdictional claims in published maps and institutional affiliations.

Copyright: (c) 2021 by the authors. Licensee MDPI, Basel, Switzerland. This article is an open access article distributed under the terms and conditions of the Creative Commons Attribution (CC BY) license (https:/ / creativecommons.org/licenses/by/ $4.0 /)$.

\begin{abstract}
The influence of pre-stretch on the mechanical properties of $2219 \mathrm{Al}$ alloys sheets were systematically investigated, with the aim of examining the age-strengthening in parts draw-formed from as-quenched sheets. The precipitation was characterized based on differential scanning calorimetry (DSC) analysis and transmission electron microscope (TEM) observation of specimens of as-quenched and quenched-stretched condition to address the influence of pre-stretching. A tensile test was performed to evaluate the effect on mechanical properties. The introduction of pre-stretching endues increased yield strength (YS) and thus can be helpful to exert the potential of the alloy. Peak YS of 387.5 and $376.8 \mathrm{MPa}$ are obtained when specimens pre-stretched for $10 \%$ are aged at 150 and $170{ }^{\circ} \mathrm{C}$, respectively, much higher than that obtained in the non-stretched specimens (319.2 MPa). The precipitation of Guinier-Preston zone (G.P. zones) and the transition to $\theta$ " shifts to a lower temperature when pre-stretched is performed. The high density of dislocations developed during the stretching contributes to the acceleration in precipitation. Quench-stretched specimens present a much quicker age-hardening response at the beginning stage, which endue higher peaked yield strength. The yield strength, however, decrease much more quickly due to the recovery that occurs during the aging processes. The study suggested the feasibility of aging draw-formed components of $2219 \mathrm{Al}$ alloy to obtain high strength.
\end{abstract}

Keywords: Al-Cu alloy; pre-stretch; cold-work strengthening; age-hardening; tensile properties

\section{Introduction}

Aluminum alloys of Al-Cu series have been widely applied in the spacecraft industry for fabricating thin wall components including cabins, tanks, and fuselages, for their high specific stiffness, high specific strength, and the good weld ability [1-5]. Most thin wall components are fabricated through draw-forming in which tempered sheets are drawn against dies to form certain curves. The fabricated components then need to be put into solution-aging treatment to achieve age-strengthening. Severe distortion, however, may occur in formed components when quenched. The post forming quench-aging procedure sometimes then must be canceled to avoid the quench-induced distortion, which wastes the age-strengthening potential of $\mathrm{Al}-\mathrm{Cu}$ alloys. A possible way to solve the problem is to form $\mathrm{Al}-\mathrm{Cu}$ sheets of solution condition into the final shape and then age the drawformed components to achieve high strength. The age-strengthening effect developed in the post-forming aging can be crucial for performance tailoring. For instance, the fabricating process of fuselages indicates that plastic strain up to $15 \%$, which is much larger than that applied in the conventional prior-aging stretching, develops in the component during the 
draw-forming process. The large cold stretching applied during the forming, together with the subsequent aging, will then lead to increased mechanical performance in the finished fuselages. To figure out the effect of pre-stretch in a wide range is then a basic mission for designing fabricating process for thin wall components.

The precipitation sequence of $\mathrm{Al}-\mathrm{Cu}$ alloys has been investigated extensively [6-10] and the effect of the stretch prior to aging on the precipitation has been of specific concern [11-15]. Small amounts (1 8\%) of pre-stretch were observed to enhance the age hardening response in a few of Al-Cu-x alloys [13-15]. For instance, Ünlü [13] observed an enhanced age-hardening in an $\mathrm{Al}-\mathrm{Cu}-\mathrm{Mg}$ alloy both in natural and artificial aging process when $6 \%$ of pre-stretch was carried out in specimens of solution condition. Ringer [14] also observed a similar effect in pre-stretched specimens at the early stage of natural aging. It was also noted [16] that the yield strength of 2219 forgings increased by $26.2 \%$ when a $3 \%$ pre-deformation was introduced before putting into aging. The increase in strength was attributed to the combined effects of heterogeneous nucleation and growth of precipitates at dislocations due to the pre-deforming. The intensified aging-hardening is believed to root from the enhanced precipitation. It was noted that the introducing of pre-strain can stop the formation of GP zone and facilitate the precipitation of $\theta^{\prime}$-phases and $S^{\prime}$-phase along dislocations [17]. Specifically, the interaction between gliding dislocations and $\mathrm{Cu}$ atoms leads to the forming of the $\theta^{\prime}$-phase. Liu [18] introduced deformation of $2 \%$ to $\mathrm{Al}-\mathrm{Cu}$ alloy and observed an increased age-hardening response, which was associated with the accelerated heterogeneous formation of $\theta^{\prime}$ precipitates on dislocations. The presence of high density of dislocations that developed during the deformation is believed promote the aging since they can serve as preferential matrix nucleation and growth sites for precipitates [19]. Ringer [14] observed that the application of a mechanical stretch enhanced the nucleation of $\theta^{\prime}$ phases in $\mathrm{Al}-\mathrm{Cu}-\mathrm{Mg}$ alloy, leading to a more uniform dispersion of precipitates.

Besides the effect on age strengthening, the prior-age stretch may also introduce cold work hardening and therefore endue increased strength to quench-stretched $\mathrm{Al}-\mathrm{Cu}$ alloy sheets. This strengthening originates from the establishing of high density of dislocations that occurs during the stretching. It could depredate during the aging process due to the recovery when high aging temperature is applied, and the influence should be taken into account.

To compare with the previous study, in which stretch up to $8 \%$ was applied, the draw-forming can induce strain up to $15 \%$ to the final components. The effect of pre-stretch can thus be quite different. It is necessary to examine the effect of a larger amount of prior-aging stretch, aiming to design post-forming aging process for thin-wall components of $\mathrm{Al}-\mathrm{Cu}-\mathrm{x}$ alloys. The current study thus aims to investigate the effect of pre-stretch on the precipitation and the mechanical performances of Al-Cu alloy. Two levels of temperature $\left(150\right.$ and $170{ }^{\circ} \mathrm{C}$ ) and three levels of pre-stretch up to $15 \%$ were selected to address the influences of the cold work and the subsequent aging in $2219 \mathrm{Al}$ alloy.

\section{Experimental}

$2219 \mathrm{Al}$ alloys plate of $\mathrm{T} 6$ temper was selected as the starting material in the current study. The chemical composition of the alloy is shown in Table 1. The specimens used for the tensile test were cut off from the plate along the rolling direction of the plate and ground carefully before putting into the solution treatment. The cross-section of the samples was $6 \times 1.5 \mathrm{~mm}^{2}$ and the gauge length was $18 \mathrm{~mm}$. The specimens were solution treated in $\mathrm{NaNO}_{3+} \mathrm{KNO}_{3}$ molten salt for 20 min at $535 \pm 3{ }^{\circ} \mathrm{C}$ before being quenched with cold water. Some specimens were stretched for 5\%, 10\% and $15 \%$ on an Instron 5569 tensile testing system at a strain rate of $2 \mathrm{~mm} / \mathrm{min}$ before putting into aging. An extensometer was used to monitor the strain within the gauge, aiming to terminate the pre-tension timely. The quenched and quenched-stretched specimens were then aged at 150 and $170{ }^{\circ} \mathrm{C}$ for $2,4,8,12$, and $16 \mathrm{~h}$, respectively. All these specimens were then put into the tensile testing on an tensile testing system (Instron 5569, Instron ITW, Norwood, MA, 
USA) at a strain rate of $2 \mathrm{~mm} / \mathrm{min}$, referring the standard of GB228-87. Three specimens were used for the tensile testing for each condition and the averaged data were used for evaluating the mechanical properties of specimens. The schematics of the sampling process are demonstrated in Figure 1.

Table 1. Chemical composition ( $w t \%)$ of the 2219 aluminum alloy.

\begin{tabular}{ccccccc}
\hline $\mathbf{C u}$ & $\mathbf{M n}$ & $\mathbf{V}$ & $\mathbf{Z r}$ & $\mathbf{F e}$ & $\mathbf{S i}$ & Al \\
\hline 6.12 & 0.33 & 0.10 & 0.13 & 0.13 & 0.046 & Bal. \\
\hline
\end{tabular}

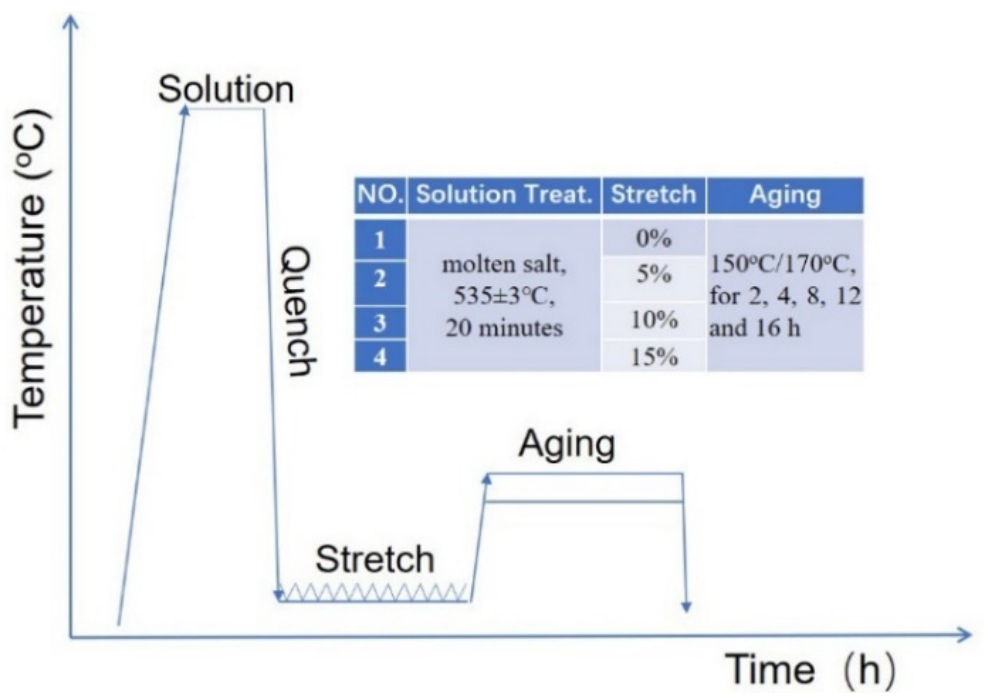

Figure 1. Schematics of the sampling plot in the current research.

Foils for transmission electron microscope (TEM, JEOL 2100, Tokyo, Japan) observation and differential scanning calorimetry (DSC) analysis were cut from the tensile specimens aged to various conditions. Foils selected for thermodynamics analysis were carefully polished to remove the surface layer before putting into the DSC system (Q2000, TA Instruments, New Castle, DE, USA) for analysis. Foils selected for TEM observation were mechanically polished to below $50 \mu \mathrm{m}$ and then electro-thinned to fabricate the specimens. The microstructure was observed on a TEM and representative morphology and selected area electron diffraction (SAED) patterns were recorded for subsequent investigation. The strength of specimens of various conditions was measured on a Instron5569 tensile testing machine.

\section{Results and Discussion}

DSC was utilized to analyze the precipitation process of quench-stretched specimens. As a reference, DSC analysis was also performed on quench-aged specimens. The DSC curve of the specimen quenched and aged at $170{ }^{\circ} \mathrm{C}$ for $2 \mathrm{~h}$ presents two distinct endothermic peaks together with two exothermic peaks in $20 \sim 400^{\circ} \mathrm{C}$ range, as shown in Figure 2a. The first endothermic peak detected at $204^{\circ} \mathrm{C}$ is associated with the G.P. zones' dissolution. This peak covers the $164 \sim 225^{\circ} \mathrm{C}$ range, indicating a long-lasting dissolution. The second endothermic peak located at $241.4^{\circ} \mathrm{C}$ is most likely attributed to the dissolution of $\theta^{\prime \prime}$ phases. The exothermic peak observed at $305.3^{\circ} \mathrm{C}$ is attributed to the forming of $\theta^{\prime}$ phases. The forming of $\theta$ phases contributes to the exothermic peak at $457.7^{\circ} \mathrm{C}$. The DSC curve is quite similar to that observed in Son [20] and Takeda [21], revealing the presences of G.P. zones, $\theta^{\prime \prime}$ phases and their transition to $\theta^{\prime}$ and further $\theta$ phases. 

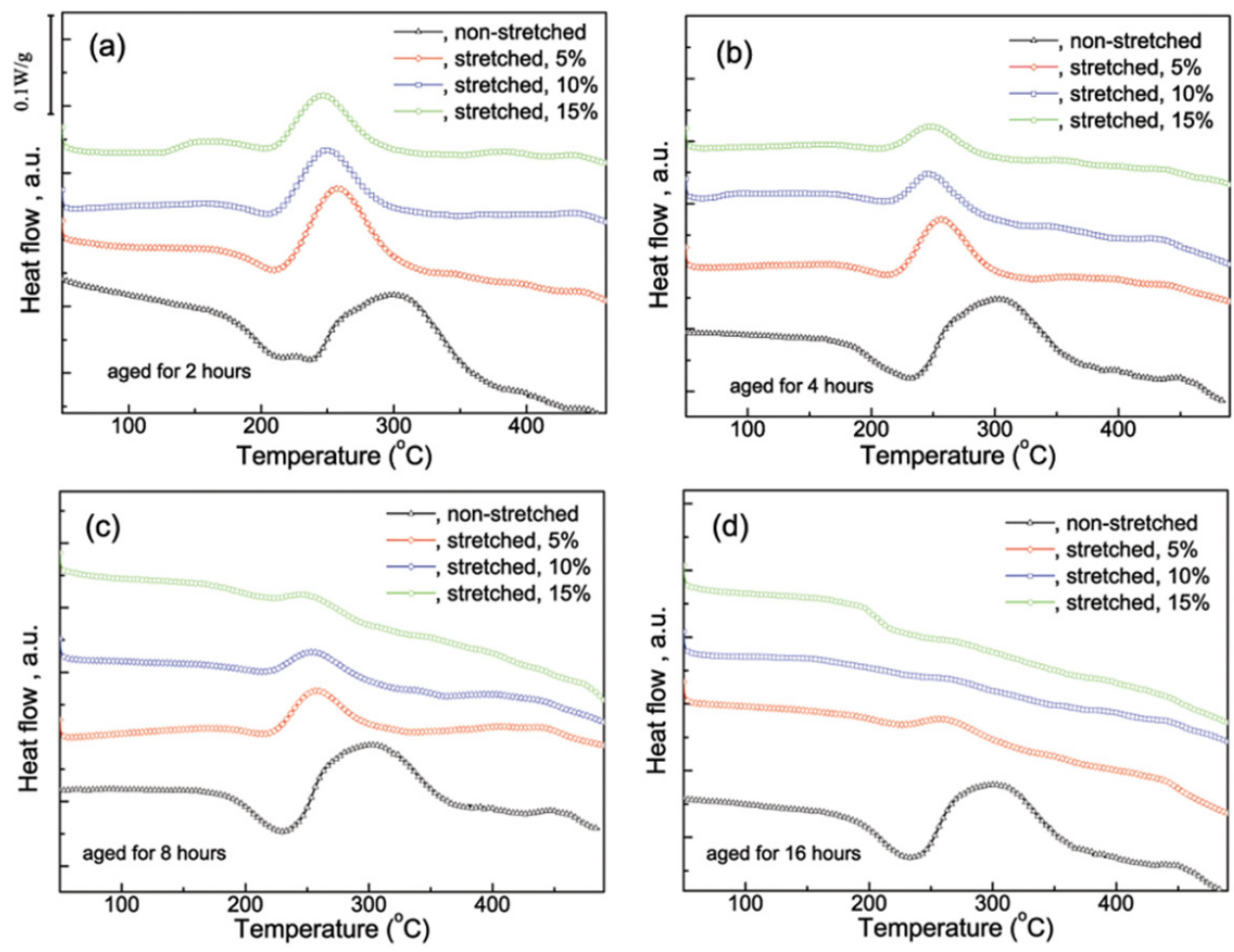

Figure 2. The DSC curves of as-quenched and quench-stretched specimens after aged at $170{ }^{\circ} \mathrm{C}$ for (a) $2 \mathrm{~h},($ b) $4 \mathrm{~h}$, (c) $8 \mathrm{~h}$ and (d) $16 \mathrm{~h}$.

The DSC curves of quenched-stretched specimens are quite different, as shown in Figure 2a. The endothermic peak associated with G.P. zones' dissolution disappears when the specimens are aged for more than $2 \mathrm{~h}$, indicating the absence of G.P. zones. The endothermic peak associated with the dissolution of $\theta^{\prime \prime}$ phases is observed shift to lower temperature. Specifically, the peak shifts from 241.4 to $209.4{ }^{\circ} \mathrm{C}, 204.6$ and $203.2{ }^{\circ} \mathrm{C}$ respectively as $5 \%, 10 \%$ and $15 \%$ stretch is applied. Also, the exothermic peak corresponding to $\theta^{\prime}$ phases' precipitation is observed shift to lower temperature as increased pre-stretch applied. This shift suggests that the dissolution of $\theta^{\prime \prime}$ and the precipitation of $\theta^{\prime}$ phases occur at lower temperature to compare with the non-stretched specimens [22,23].

When aged for $4 \mathrm{~h}$, only one endothermic peak and two exothermic peaks can be distinguished in the DSC curve of the non-stretched specimen, as shown in Figure $2 b$. The endothermic peak that located at $231^{\circ} \mathrm{C}$ is attributed to the dissolution of $\theta^{\prime \prime}$ phases, meaning the presence of $\theta^{\prime \prime}$ phases and the absence of G.P. zones. When stretch is applied, the peak corresponding to the $\theta^{\prime \prime}$ phases' dissolution shifts to lower temperature, similar to that observe in the case of $2 \mathrm{~h}$. Meanwhile, the endotherm origins from $\theta^{\prime \prime}$ dissolution became weaker gradually as the stretch increases, indicating the decreased amount of remained $\theta^{\prime \prime}$ phases. The DSC curves of specimens aged for $8 \mathrm{~h}$, as shown in Figure $2 \mathrm{c}$ are similar to those observed in the case of $4 \mathrm{~h}$, but the endotherm/exotherm related to the precipitation process becomes much weaker. Specifically, the endothermic peak attributed to $\theta^{\prime \prime}$ phases' dissolution becomes very low, indicating that the amount of $\theta^{\prime \prime}$ phases is quite small. For specimens aged for $16 \mathrm{~h}$, only very weak endothermic/exothermic peaks can be distinguished on the DSC curves of stretched specimens, indicating the absence of G.P. zones and $\theta^{\prime \prime}$ phases, as shown in Figure 2d.

The DSC curves of specimens quenched, $10 \%$ stretched, and then aged at $150{ }^{\circ} \mathrm{C}$ for different times are demonstrated in Figure 3. The peaks associated with the dissolution of $\theta^{\prime \prime}$ phases and the forming of $\theta^{\prime}$ does not shift apparently, which is different to that observed in case of $170{ }^{\circ} \mathrm{C}$. These two peaks become weak gradually as the stretch increases but survive even after $16 \mathrm{~h}$ aging, indicating the remaining of $\theta^{\prime \prime}$ phases at the condition. This 
result reveals that the dissolution-precipitation is much slower at $150^{\circ} \mathrm{C}$ and the influence of pre-stretch is partially moderated in comparation to those aged at $170^{\circ} \mathrm{C}$.

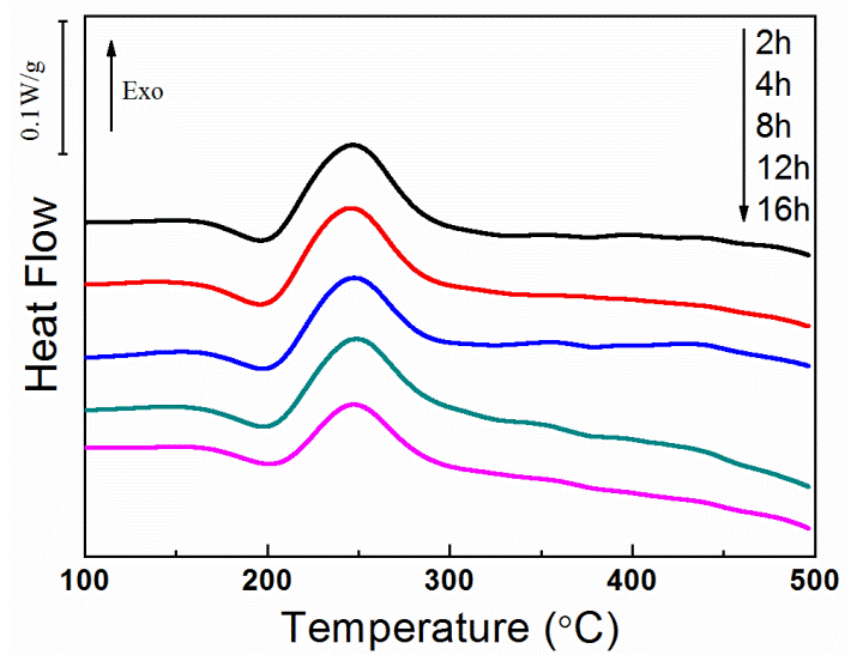

Figure 3. The differential scanning calorimetry (DSC) curves of as-quenched and $10 \%$ stretched specimens after aged at $150^{\circ} \mathrm{C}$.

The morphology and the corresponding SAED of precipitates in specimens stretched for various amount and aged at $170{ }^{\circ} \mathrm{C}$ for $4 \mathrm{~h}$ are shown in Figure 4 . High density of precipitates is observed shape up on the matrix in the non-stretched specimen. Most precipitates are $20 \sim 30 \mathrm{~nm}$ in length and $2 \sim 4 \mathrm{~nm}$ in thickness. The SAED pattern in Figure $4 \mathrm{~b}$ indicates that most precipitates observed at this condition are $\theta^{\prime \prime}$ phases. The precipitation and coarsening accelerate apparently when $5 \%$ stretching is performed as substantive $\theta^{\prime}$ phases are observed, as shown in Figure $4 \mathrm{c}, \mathrm{d}$. These $\theta^{\prime}$ phases are $57 \mathrm{~nm}$ averagely in length and around $5 \mathrm{~nm}$ in thickness. A very fine $\theta^{\prime \prime}$ phase can be observed in intervals although the amount decreases, as demonstrated in the SAED pattern in Figure $4 \mathrm{~d}$. When the pre-stretch is further increased to $10 \%, \theta^{\prime}$ phase increases in number density but does not change apparently in size. The $\theta^{\prime}$ phase in the $10 \%$ pre-stretched specimen was $58 \mathrm{~nm}$ averagely. Fine $\theta^{\prime \prime}$ phase can still be distinguished on the matrix, as demonstrated at the morphology in Figure 4e and the SAED in Figure 4f. When the pre-stretch is eventually increased to $15 \%$, the morphology and the SAED patterns in Figure $4 \mathrm{~g}$, h revealed that the precipitates are mainly $\theta^{\prime}$ phase along with a small amount of $\theta^{\prime \prime}$ phase. The amount of the $\theta^{\prime}$ phases increase slightly in comparation with that in case of $10 \%$ stretching. The size of the $\theta^{\prime}$ phases is measured as $57 \mathrm{~nm}$, which does not change significantly with further increased amount of pre-stretching.

The increase in $\theta^{\prime}$ and the according decrease of $\theta^{\prime \prime}$ suggest that the pre-stretching facilitates the precipitation process. Specifically, it induces an accelerated development of $\theta^{\prime}$ when aged at $170{ }^{\circ} \mathrm{C}$. The high density of dislocations that developed during the stretching are believed to enhance the precipitation of $\theta^{\prime}$ phases. In fact, the increase in dislocation density was proved in a previous research. The research [17] noted that the dislocation density in the as-quenched condition was low $\left(\sim 2 \times 10^{12} \cdot \mathrm{m}^{-2}\right)$ but increases quickly by a factor of 100 or even higher when stretching was introduced. For instance, the dislocation density reaches at a high level of $1.8 \times 10^{14} \cdot \mathrm{m}^{-2}$ when a strain of $7 \%$ was introduced. The high density of dislocation facilitates $\theta^{\prime}$ phases' preferential separation from the matrix since $\theta^{\prime}$ phases prefer to nucleate on dislocations to compare with $\theta^{\prime \prime}$. Meanwhile, the high deformation stored energy accumulated during stretching helps to decrease the nucleation barriers [24]. On the other hand, the transition from existing $\theta^{\prime \prime}$ phases to $\theta^{\prime}$ phases can also be enhanced since the high density of dislocation induce an increased diffusion. Additionally, the depletion of Cu due to the $\theta^{\prime \prime}$ phases' preferential precipitation may further suppress the precipitation of $\theta^{\prime}$ phases. 

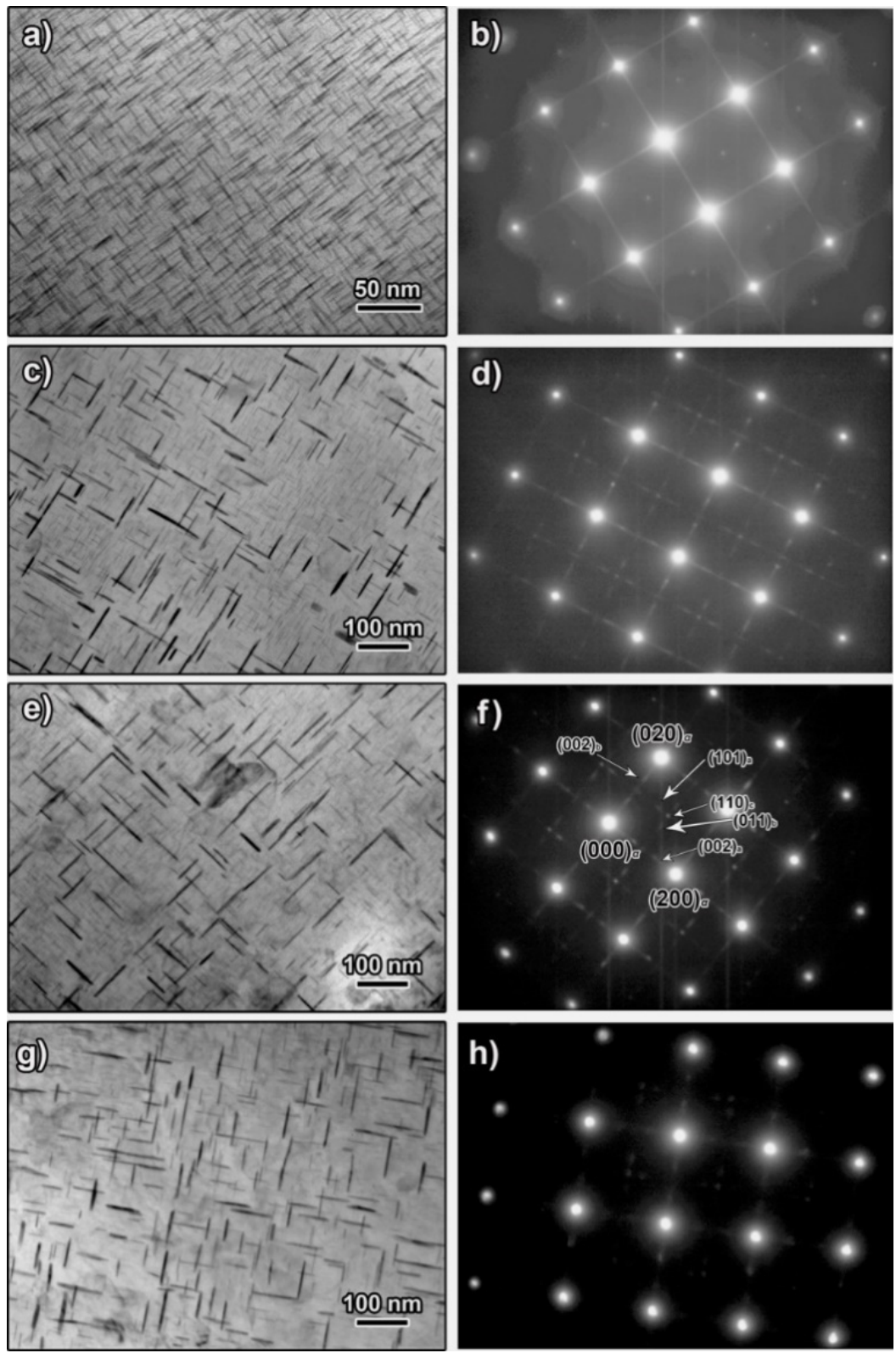

Figure 4. TEM morphology and corresponding selected area electron diffraction (SAED) patterns demonstrating the microstructure of specimens aged at $170{ }^{\circ} \mathrm{C}$ for $4 \mathrm{~h}$. The specimens were nonstretched, (a,b), and then stretched for $5 \%,(\mathbf{c}, \mathbf{d}), 10 \%,(\mathbf{e}, \mathbf{f})$ and $15 \%,(\mathbf{g}, \mathbf{h})$.

The precipitates in specimens stretched $10 \%$ and then aged for $16 \mathrm{~h}$ at $170{ }^{\circ} \mathrm{C}$ and $150{ }^{\circ} \mathrm{C}$ were observed on TEM, as shown in Figure 5. $\theta^{\prime}$ phases are observed everywhere but $\theta^{\prime \prime}$ phases can hardly be observed in the specimen aged at $170{ }^{\circ} \mathrm{C}$ for $16 \mathrm{~h}$, as shown in Figure $5 a, b$. This observation is consistent with the DSC analysis, revealing $\theta^{\prime \prime}$ phases' fully transition to $\theta^{\prime}$ phases. The $\theta^{\prime}$ precipitates are $68 \mathrm{~nm}$ in length and 5-10 $\mathrm{nm}$ in thickness, a little larger than those in the specimen aged for $4 \mathrm{~h}$. The morphology together with the SAED patterns demonstrated in Figure $5 \mathrm{c}, \mathrm{d}$ reveals the coexisting of $\theta^{\prime \prime}$ and $\theta^{\prime}$ phases when aged at $150{ }^{\circ} \mathrm{C}$ for $16 \mathrm{~h}$, which is also consistent to the DSC analysis. The $\theta^{\prime}$ phase is $56 \mathrm{~nm}$ averagely in size in the specimen aged at $150{ }^{\circ} \mathrm{C}$, which is comparable to that in the specimen peak-aged at $170{ }^{\circ} \mathrm{C}$. The comparison suggests that the precipitation kinetic is much slower at $150{ }^{\circ} \mathrm{C}$ than that at $170^{\circ} \mathrm{C}$ and the transition from $\theta^{\prime \prime}$ to $\theta^{\prime}$ cannot complete even when aged for a long time, which is similar to the previous study [25]. 


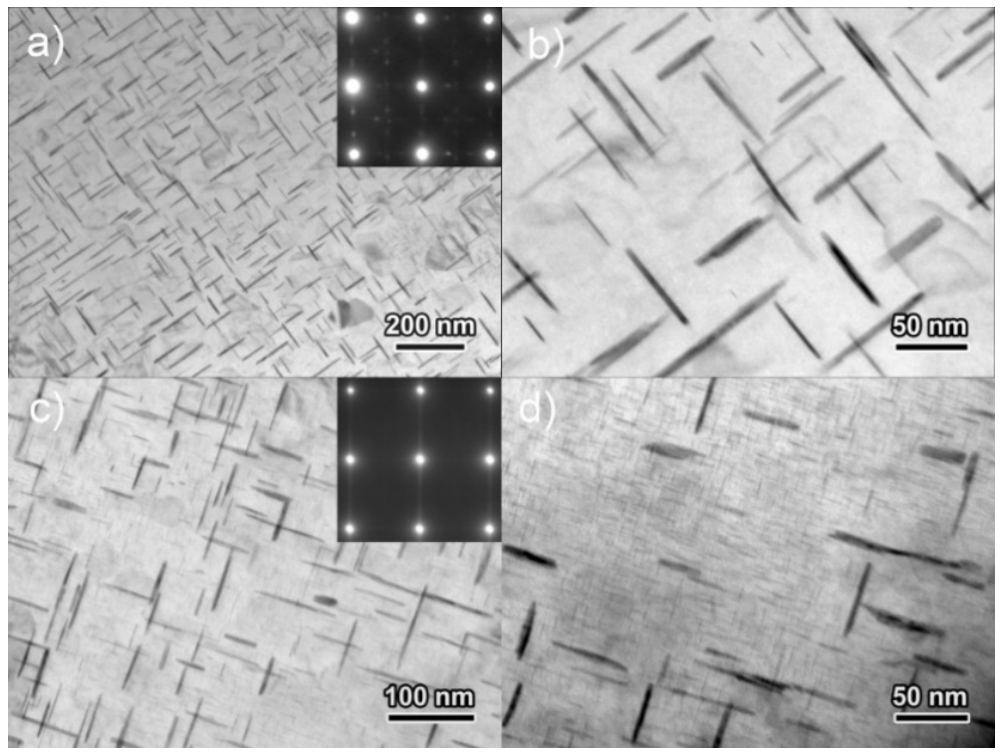

Figure 5. TEM images of the precipitates in the specimens that solution treated, stretched for $10 \%$ and then aged for $16 \mathrm{~h}$ at $170^{\circ} \mathrm{C},(\mathbf{a}, \mathbf{b})$; or at $150^{\circ} \mathrm{C},(\mathbf{c}, \mathbf{d})$.

The size distribution of $\theta^{\prime}$ phases in specimens of selected condition are shown in the histogram in Figure 6. The length distribution in specimens pre-stretched for $5 \%, 10 \%$ and $15 \%$ and aged for $4 \mathrm{~h}$ is similar to each other except that the fraction of $\theta^{\prime}$ phases with length of $30 \sim 40 \mathrm{~nm}$ is little higher in specimen pre-stretched for $5 \%$. When the aging proceeds to $16 \mathrm{~h}, \theta^{\prime}$ phases in specimen pre-stretched for $10 \%$ grow slightly, indicating a slowly developed over-aging in the alloy. It can also be deduced that the growth of $\theta^{\prime}$ phases is quite slight when the aging duration is prolonged from $4 \mathrm{~h}$ to $8 \mathrm{~h}$.
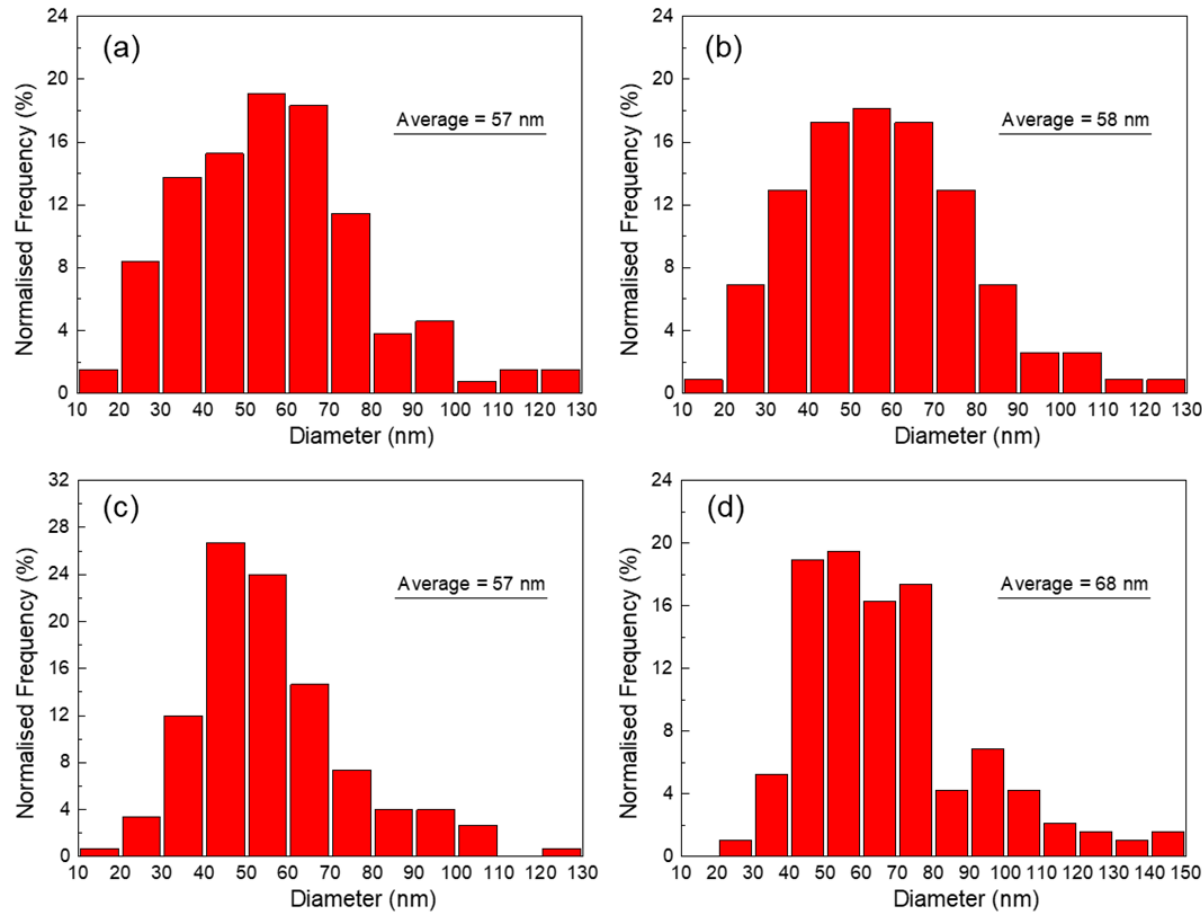

Figure 6. Size distribution of the precipitates in the specimens that processed by various ways. (a) Prestretched for $5 \%$ and aged at $170{ }^{\circ} \mathrm{C}$ for $4 \mathrm{~h}$; (b) Pre-stretched for $10 \%$ and aged at $170{ }^{\circ} \mathrm{C}$ for $4 \mathrm{~h}$; (c) Pre-stretched for $15 \%$ and aged at $170{ }^{\circ} \mathrm{C}$ for $4 \mathrm{~h}$; (d) Pre-stretched for $10 \%$ and aged at $170{ }^{\circ} \mathrm{C}$ for $16 \mathrm{~h}$. 
The mechanical performances of specimens as-quenched and quenched-stretched are demonstrated in Figure 7. The as-quenched specimen presents low yield strength (YS) of $143 \mathrm{MPa}$ but high elongation of $25.4 \%$, presenting an excellent drawing formability. The YS is found increases persistently but the elongation decreases accordingly as increased pre-stretch is performed. YS rises to $265 \mathrm{MPa}$ when $5 \%$ stretch is applied, indicating an increased deformation resistance. YS of $322 \mathrm{MPa}$ is eventually obtained when the as-quenched specimens is pre-stretched for $15 \%$, which is apparently higher than that of non-stretched specimens. The increase in the strength is evident when $5 \%$ stretched is applied and then mild off when the amount of pre-stretching further increases, which is favorable for draw forming. The tensile strength (TS) increases much more slightly comparing with the yield strength. The increase in the YS together with the decrease in the elongation is dominantly attributed to the increased dislocation density. It is indicated that the contribution of existing dislocations to the TS is much less to compare with that of the YS.

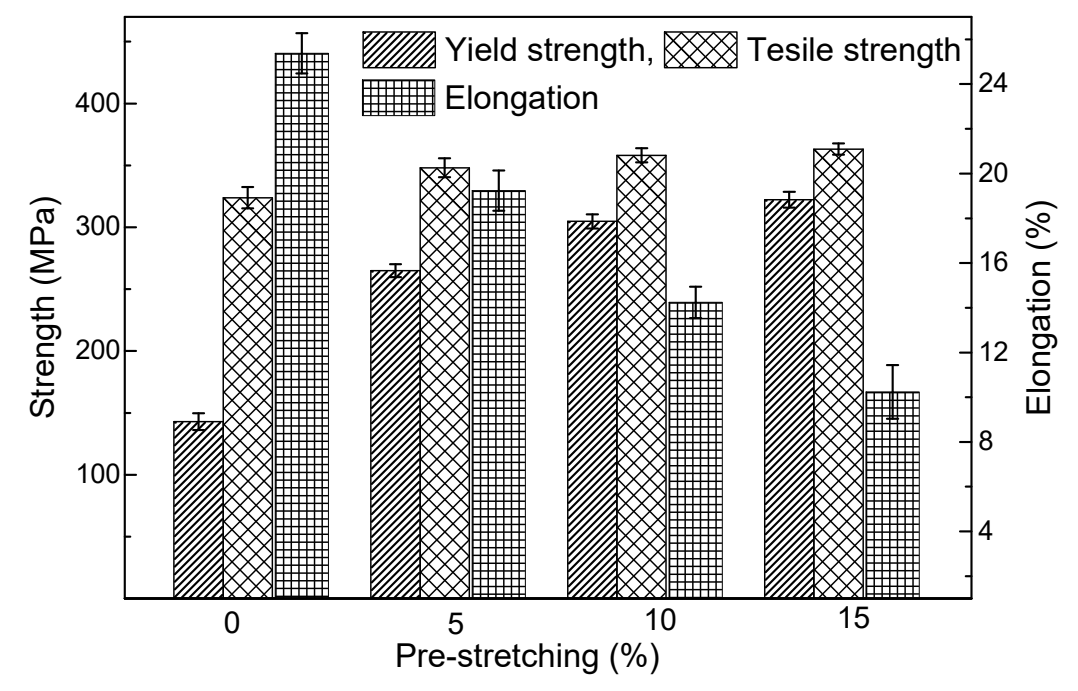

Figure 7. Mechanical performances of 2219 specimens that solution-treated and pre-stretched by various amount.

The variation in mechanical performances of as-quenched and quench-stretched specimens during the aging is shown in Figure 8. The YS of the non-stretched specimen presents a progressive response to the aging and reaches at the peak YS of $300 \mathrm{MPa}$ after aged for $12 \mathrm{~h}$. Also, the characteristic of over-aging develops quite slowly after the aging exceeds further. A much quicker increase of YS is observed at the first $4 \mathrm{~h}$ in all the prestretched specimens despite the diversity in the pre-stretching. The YS of quench-stretched specimen reached at the peak level within $4 \mathrm{~h}$, which is much earlier than that in the as-quenched specimens and peak YS of 349,372 , and $390 \mathrm{MPa}$, which is much higher than the peak YS obtained in non-stretched specimens, was observed. A decrease in YS however develops immediately after reaching the peak-aged condition, as shown in the Figure 8a, indicating the accelerated developing towards over-aging condition. The diversity of YS between specimens stretched for different amount narrows away quickly after the aging time exceeds $4 \mathrm{~h}$, and eventually disappears after $8 \mathrm{~h}$, as shown in Figure 8a. Meanwhile the stretched specimens' advantage over the non-stretched ones in YS decreases gradually from $70 \sim 100 \mathrm{MPa}$ to around $35 \mathrm{MPa}$ during the $4 \sim 8 \mathrm{~h}$. The loss of age-hardening is partially responsible for the decreased YS since the $\theta^{\prime}$ precipitates are found to coarsen quite slightly in the over-aged specimen. Moreover, the rapid decrease in YS is believed attributed to the recovery in the alloy during the aging since remarkable recovery can occur in cold-rolled 2219 sheet when aged at $175^{\circ} \mathrm{C}$ [3]. High density of dislocations that developed during the stretching annihilates quickly and their contribution to the YS then reduces. 

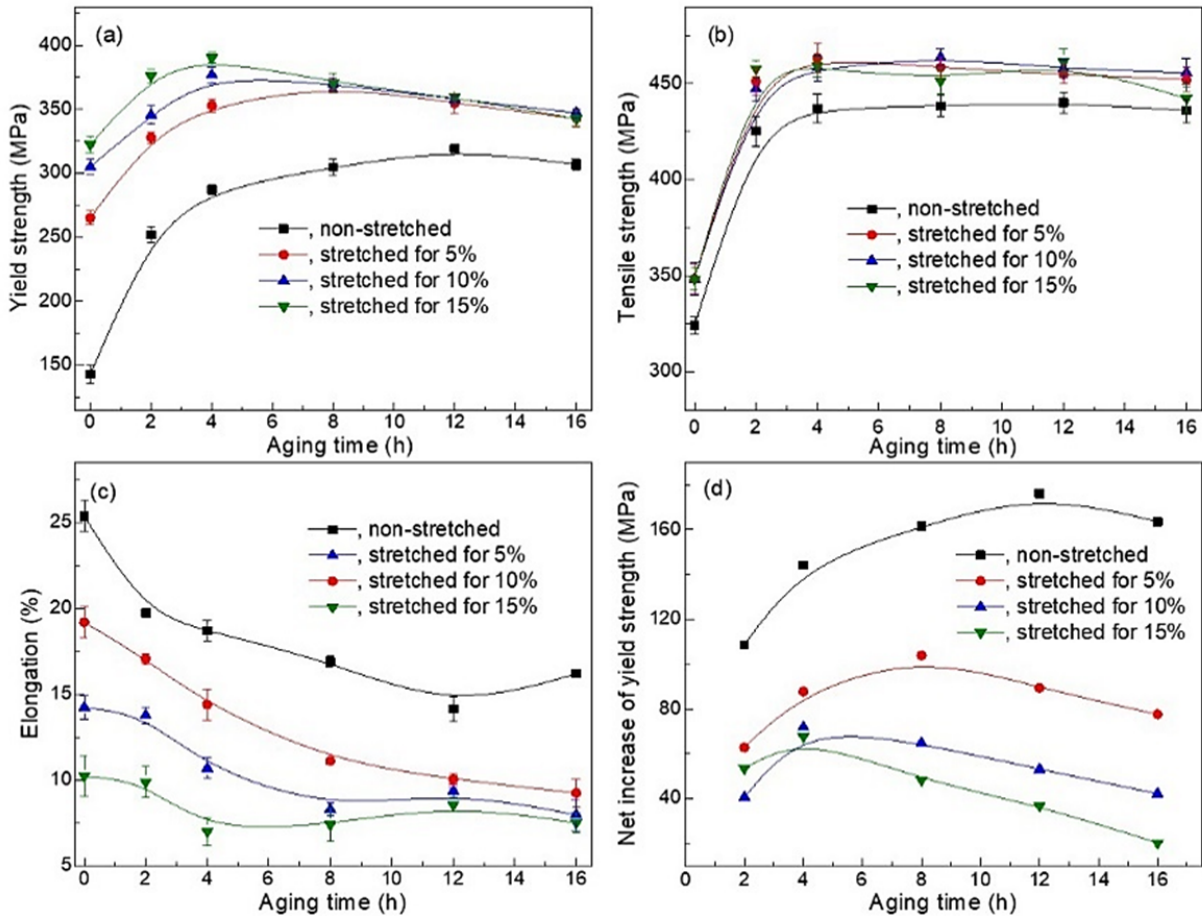

Figure 8. The performances of stretch-aged specimens, (a) yield strength, (b) tensile strength, (c) the elongation and (d), the net increase in yield strength. Specimens were stretched for $5 \%, 10 \%$ and $15 \%$ and before aged at $170{ }^{\circ} \mathrm{C}$.

The tensile strength (TS) of the specimens increases quickly within the first $4 \mathrm{~h}$ and reach at the level of $435 \mathrm{MPa}$ or $460 \mathrm{MPa}$ for the non-stretched specimens, as shown in Figure $8 \mathrm{~b}$, as the aging proceeds further. The stretched specimens present slightly higher TS comparing to the non-stretched specimens, but the amount of deformation does not influence the TS. The decrease of TS due to the over-aging, however, does not occur evidently when the aging proceeds further from the moment of $4 \mathrm{~h}$, which is quite different from that observed in the YS. The comparative observing suggests that the TS is not significantly influenced by the limited coarsening of $\theta^{\prime}$ precipitates. Moreover, the occurrence of recovery during aging is considered to have little influence on the TS. It is believed that the contribution of existing dislocations to the TS is much less to compare with that to the YS. The annihilation of dislocations, that developed in the later stage of the aging, then contributes much more to the decrease of YS than to the decrease of TS. In addition, the specimens exhibit comparable peak TS despite the different pre-stretching level. This can be adequately explained by the similar-sized $\theta^{\prime}$ phase in the peak-aged specimens that observed in Figure 4.

For all specimens, the elongation decreases as aging proceeds, as shown in Figure 8c. For each aging condition, the non-stretched specimens present much higher elongation to compare with the pre-stretched ones. For instance, the as-quenched specimen presents an elongation exceeding $26 \%$, revealing a high formability, while the elongation in nonstretched specimens decreases to $18.2 \%, 14.3 \%$, and $10.1 \%$ respectively. The decrease in the elongation is find near to that of the value of the pre-stretching for specimens of solutiontreated condition. The decrease of elongation with the increases of pre-stretching was also observed in specimens aged to same conditions despite the varied pre-stretching. Specimens of peak-aged condition exhibits elongation of $14.4 \%, 10.7 \%$, and $7.1 \%$, respectively, when pre-stretching of $5 \%, 10 \%$, and $15 \%$ were applied.

The net increase in yield strength (NIY) during the aging is calculated and the results are demonstrated in Figure 8d. The NIYs are generally lower in the quenched-stretched specimens than that in the non-stretched ones. More specifically, the NIY decreases as the 
stretching decreases. The softening related to the recovery is enhanced when lager amount of stretch is applied, which then lead to decreased NIYs.

The influence of pre-stretching on the age-hardening was also examined at $150{ }^{\circ} \mathrm{C}$ introducing a $10 \%$ of stretch. As shown in Figure 9a, the age-hardening develops quickly during the first $2 \mathrm{~h}$ and subsequently slows down. The increase of strength continues all thorough the aging with a YS of $387 \mathrm{MPa}$ obtained at $16 \mathrm{~h}$. The elongation of stretched specimens increases slightly at the beginning of aging and reaches at a peak level of $15.9 \%$. It then decreases as the aging proceeds and eventually to $11.2 \%$ after aged for $16 \mathrm{~h}$ when peak strength obtained. The YS of stretched specimens is around $100 \mathrm{MPa}$ higher than that of the non-stretched ones all through the aging process, as shown in Figure 9b, which is higher and more stable than that in case of $170^{\circ} \mathrm{C}$. The disparity between the TS is around $50 \mathrm{MPa}$ all through the aging, narrower than that in $\mathrm{YS}$, as shown in the Figure $9 \mathrm{~b}$. The recovery is believed much weak due to the lower aging temperature, which thus leads to milder decreases in strength.
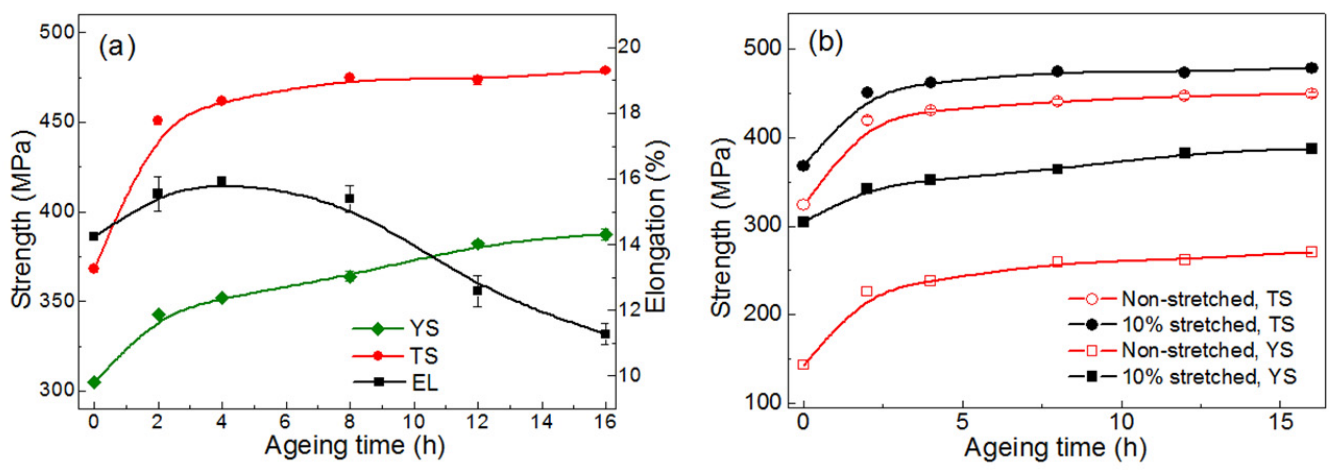

Figure 9. Mechanical properties of specimen as-quenched and stretch-aged when aged at $150{ }^{\circ} \mathrm{C},(\mathbf{a})$, and the comparing to non-stretched one's, (b).

Either aged at $150{ }^{\circ} \mathrm{C}$ or $170{ }^{\circ} \mathrm{C}$, the peak-aged condition is associated with the co-exist of small amount of $\theta^{\prime \prime}$ and fine $\theta^{\prime}$ phases, indicating fine $\theta^{\prime}$ phases contribute much more to the strength to compare with the $\theta^{\prime \prime}$ or $\theta$ phases, which is consistent with the observation in previous research $[20,26]$.

The current research presents both the intensified aging-hardening effect and the recovery induced softening that related to the prior-aging stretching within a wide range $(\sim 15 \%)$ of strain, which then extends the understanding of the stretch-aging to include the forming induced strain in. The positive response from the pre-stretching facilitates the fabricating of thin wall components along a newly proposed route of solution $\rightarrow$ draw forming $\rightarrow$ aging through which the precise forming and the aging-strength of $\mathrm{Al}-\mathrm{Cu}$ alloy can be accomplished synergistically. Moreover, intensified precipitation, together with the enhanced aging-strengthening, due to the pre-stretching, has also been noted in the Agbearing $\mathrm{Al}-\mathrm{Cu}-\mathrm{Mg}$ alloys. Some research observed that the introducing of pre-stretching contribute to refining of $\Omega$-phase and uniform dispersion of $\theta^{\prime}$-phase [14]. Pre-stretching is believed to disrupt the clustering of $\mathrm{Ag}-\mathrm{Mg}$ with $\mathrm{Cu}$ atoms, which blocks the forming of GP zones and thereafter facilitates the precipitation of the $\theta^{\prime}$-phase [16]. The effect of stretching is similar in Ag-free and Ag-bearing Al-Cu-Mg alloy, which then extend the scope of the "solution $\rightarrow$ draw forming $\rightarrow$ aging" route.

\section{Conclusions}

(1) The as-quenched 2219 alloy presents low YS (143 MPa) together with a high elongation $(25.4 \%)$ during the tensile test, inferring an excellent formability in draw-forming processes.

(2) The introducing of pre-stretch endues increased YS and thus can be helpful to exert the potential of the alloy. YS of 387.5 and $376.8 \mathrm{MPa}$ is obtained when specimens 
pre-stretched for $10 \%$ is aged at 150 and $170{ }^{\circ} \mathrm{C}$ respectively, much higher than that of the peaked YS observed in the non-stretched specimens (319.2 MPa).

(3) The precipitation of G.P. zones and the transition to $\theta^{\prime \prime}$ shifts to lower temperature when as-quenched $\mathrm{Al}-\mathrm{Cu}$ alloy sheet is stretched for more than $5 \%$. The high density of dislocations developed during the stretching contributed to the acceleration in precipitation. Precipitates in stretched specimens are mainly $\theta^{\prime}$-phase while mixed precipitates (mainly $\theta^{\prime \prime}$ and minor $\theta^{\prime}$ ) developed in non-stretched specimens.

(4) Quench-stretched specimens present a much quicker age-hardening at the beginning stage, which endue higher peak YS. The YS, however, decrease much more quickly due to the recovery that occurs during the aging processes.

(5) The current study thus indicates the feasibility of draw-forming thin-wall component of $\mathrm{Al}-\mathrm{Cu}$ alloys and to obtained high strength via post-forming aging.

Author Contributions: G.-A.L., J.-T.J. and L.Z. conceived and designed the study. G.-A.L. and Z.M. performed the experiments. J.-T.J. and W.L. wrote the paper. G.-A.L., W.-Z.S. and L.Z. reviewed and edited the manuscript. W.-Z.S. project administration. W.-Z.S. funding acquisition. All authors have read and agreed to the published version of the manuscript.

Funding: This work was financially supported by Natural Science Foundation of China under Grant (No. 51971077 and U1737206).

Institutional Review Board Statement: Not applicable.

Informed Consent Statement: Not applicable.

Data Availability Statement: The data presented in this study are available on request from the corresponding author.

Acknowledgments: Thank Li Yang for TEM observing and the fruitful discussion.

Conflicts of Interest: The authors declare no conflict of interest.

\section{References}

1. Huang, X.D.; Zhang, H.; Han, Y.; Wu, W.X.; Chen, J.H. Hot deformation behavior of 2026 aluminum alloy during compression at elevated temperature. Mater. Sci. Eng. A 2010, 527, 485-490. [CrossRef]

2. Zhang, J.; Chen, B.Q.; Zhang, B.X. Effect of initial microstructure on the hot compression deformation behavior of a 2219 aluminum alloy. Mater. Des. 2012, 34, 15-21. [CrossRef]

3. Pantelakis, S.G.; Alexopoulos, N.D. Assessment of the ability of conventional and advanced wrought aluminum alloys for mechanical performance in light-weight applications. Mater. Des. 2008, 29, 80-91. [CrossRef]

4. Srivatsan, T.S.; Vasudevan, S.; Park, L.; Lederich, R.J. The quasi-static deformation and final fracture behavior of aluminum alloy 2219. Mater. Sci. Eng. A 2008, 497, 270-277. [CrossRef]

5. Babu, S.; Ram, G.D.; Venkitakrishnan, P.V.; Reddy, G.M.; Rao, K.P. Microstructure and Mechanical Properties of Friction Stir Lap Welded Aluminum Alloy AA2014. J. Mater. Sci. Technol. 2012, 28, 414-426. [CrossRef]

6. Papazian, J.M. A calorimetric study of precipitation in aluminum alloy 2219. Metal. Trans. A 1981, 12, 269-280. [CrossRef]

7. Papazian, J.M. Calorimetric Studies of Precipitation and Dissolution Kinetics in Aluminum Alloys 2219 and 7075. Metal. Trans. A 1982, 13, 761-769. [CrossRef]

8. Chen, Y.; Zhang, Z.; Tsalanidis, A.; Weyland, M.; Medhekar, N.V.; Bourgeois, L. The enhanced theta-prime $\left(\theta^{\prime}\right)$ precipitation in an Al-Cu alloy with trace Au additions. Acta Mater. 2017, 125, 340-350. [CrossRef]

9. Gorbatov, O.I.; Gornostyrev, Y.N.; Korzhavyi, P.A. Many-body mechanism of Guinier-Preston zones stabilization in Al-Cu alloys. Scr. Mater. 2017, 138, 130-133. [CrossRef]

10. Liu, H.; Bellón, B.; Llorca, J. Multiscale modelling of the morphology and spatial distribution of $\theta^{\prime}$ precipitates in Al-Cu alloys. Acta Mater. 2017, 132, 611-626. [CrossRef]

11. Kaibyshev, R.; Kazakulov, I.; Gromov, D.; Musin, F.; Lesuer, D.R.; Nieh, T.G. Superplasticity in a 2219 aluminum alloy. Scr. Mater. 2001, 44, 2411-2417. [CrossRef]

12. Kaibyshev, R.; Sitdikov, O.; Mazurina, I.; Lesuer, D.R. Deformation behavior of a $2219 \mathrm{Al}$ alloy. Mater. Sci. Eng. A 2002, 334, 104-113. [CrossRef]

13. ÜNLÜ, N.; Gable, B.M.; Shiflet, G.J.; Starke, E.A. The effect of cold work on the precipitation of $\Omega$ and $\theta^{\prime}$ in a ternary Al-Cu-Mg alloy. Metall. Mater. Trans. A 2003, 34, 2757-2769. [CrossRef]

14. Ringer, S.P.; Muddle, B.C.; Polmear, I.J. Effects of cold work on precipitation in Al-Cu-Mg-(Ag) and Al-Cu-Li-(Mg-Ag) alloys . Metall. Mater. Trans. A 1995, 26, 1659-1671. [CrossRef] 
15. Quan, L.; Zhao, G.; Sam, G.; Barry, C.M. Effect of pre-stretching on microstructure of aged 2524 aluminum alloy. Trans. Nonferr. Metal. Soc. 2011, 21, 1957-1962. [CrossRef]

16. Gazizov, M.; Kaibyshev, R. Effect of pre-straining on the aging behavior and mechanical properties of an $\mathrm{Al}-\mathrm{Cu}-\mathrm{Mg}-\mathrm{Ag}$ alloy. Mater. Sci. Eng. A 2015, 625, 119-130. [CrossRef]

17. Ma, P.P.; Liu, C.H.; Wu, C.L.; Liu, L.M.; Chen, J.H. Mechanical properties enhanced by deformation-modified precipitation of $\theta^{\prime}$-phase approximants in an Al-Cu alloy. Mater. Sci. Eng. A 2016, 676, 138-145. [CrossRef]

18. Liu, C.; Ma, Z.; Ma, P.; Zhan, L.; Huang, M. Multiple precipitation reactions and formation of $\theta^{\prime}$-phase in a pre-deformed Al-Cu alloy. Mater. Sci. Eng. A 2018, 733, 28-38. [CrossRef]

19. Yoshimura, R.; Konno, T.J.; Abe, E.; Hiraga, K. Transmission electron microscopy study of the evolution of precipitates in aged Al-Li-Cu alloys: The $\theta^{\prime}$ and $\mathrm{T}_{1}$ phases. Acta Mater. 2003, 51, 4251-4266. [CrossRef]

20. Son, S.K.; Takeda, M.; Mitome, M.; Bando, Y.; Endo, T. Precipitation behavior of an Al-Cu alloy during isothermal aging at low temperatures. Mater. Lett. 2005, 59, 629-632. [CrossRef]

21. Takeda, M.; Maeda, Y.; Yoshida, A.; Endo, T. Discontinuity of G.P.(I) zone and $\theta^{\prime}$-phase in an Al-Cu alloy. Scr. Mater. 1999, 41, 643-649. [CrossRef]

22. Gao, N.; Davin, L.; Wang, S.; Cerezo, A.; Starink, M.J. Precipitation in Stretched Al-Cu-Mg Alloys with Reduced Alloying Content Studied by DSC, TEM and Atom Probe. Mater. Sci. Forum 2002, 396-402, 923-928. [CrossRef]

23. Starink, M.J. A calorimetric study of precipitation in an Al-Cu alloy with silicon particles. Metal. Trans. A 1991, 22, 665-674. [CrossRef]

24. Gable, B.M.; Zhu, A.W.; Csontos, A.A.; Starke, E.A. The role of plastic deformation on the competitive microstructural evolution and mechanical properties of a novel Al-Li-Cu-X alloy. Light Met. 2001, 1, 1-14. [CrossRef]

25. Chen, Y.C.; Feng, J.C.; Liu, H.J. Precipitate evolution in friction stir welding of 2219-T6 aluminum alloys. Mater. Charact. 2009, 60, 476-481. [CrossRef]

26. Wyss, R.K.; Sanders, R.E. Microstructure-property relationship in a 2xxx aluminum alloy with mg addition. Metal. Trans. A 1988, 19, 2523-2530. [CrossRef] 